\title{
An Improved Method for Evaluating Testosterone Biosynthetic Defects
}

\author{
FRED I. CHASALOW, ${ }^{(23)}$ SANDRA L. BLETHEN, HARRY B. MARR, AND FRANK S. FRENCH \\ Edward Mallinckrodt Department of Pediatrics, Washington University School of Medicine, St. Louis, Missouri \\ USA, the Chemistry and Life Science Group, Research Triangle Institute, Research Triangle Park, North \\ Carolina USA and the Department of Pediatrics, University of North Carolina, Chapel Hill, North Carolina USA
}

\begin{abstract}
Summary
A double-label, double-substrate incubation technique has been developed and used to study the conversion of progesterone to testosterone in testes extracts from incompletely virilized males. The procedure involves separation of the microsomes from a testicular homogenate, incubating the microsomes with $1 \mu \mathrm{M}$ [7$\left.{ }^{3} \mathrm{H}\right]$ progesterone, $1 \mu \mathrm{M} 17$-hydroxy $\left[4-{ }^{14} \mathrm{C}\right.$ progesterone, and 0.25 $\mathrm{mM}$ NADPH in pH 7.4 phosphate buffer at $37^{\circ} \mathrm{C}$. Steroid precursors and products are separated by column chromatography on Sephadex LH-20 with a solvent system of isoctane:ethyl acetate:methanol (4:1:1 by volume). These procedures can be completed in 2 days, and thus the method represents an improvement in time, reproducibility, and simplicity when compared to techniques based on thin layer or paper chromatography.

The method has been used to distinguish the biochemical abnormality in three cases with XY sex chromatin, posterior labial fusion, clitoromegaly, and hypospadias. The abnormalities identified were: Case 1 , no defect in testosterone synthesis (probable androgen insensitivity); Case 2, 17-ketosteroid reductase deficiency; and Case 3, steroid-17,20-lyase deficiency.
\end{abstract}

\section{Abbreviation}

hCG, human chorionic gonadotropin

Enzymatic defects in the biosynthesis of testosterone can be tentatively distinguished by hCG stimulation tests $(8,15)$ and the diagnosis can be confirmed by in vitro testicular incubation after surgery. However, the classical techniques based on thin layer (11) or paper chromatography (6) are laborious and time consuming. We have developed a method based on doublesubstrate, double-label incubation and Sephadex LH-20 chromatography that can confirm these diagnoses simply and rapidly. The method depends for its success on the reproducibility of the Sephadex LH-20 columns and on the double label method of incubation of the tissue with the steroid substrates. A preliminary report of the procedure and results has appeared (3).

\section{MATERIALS AND METHODS}

The procedures for the isolation of microsomes from human testes and the incubation techniques are similar to those described in detail elsewhere using rat testes (2). Briefly, fresh testicular tissue was homogenized in 3 volumes $(\mathrm{w} / \mathrm{v})$ of $0.25 \mathrm{M}$ sucrose and the microsomes were collected by differential centrifugation between 11,000 and $105,000 \times g$, resuspended at a dilution of $1 \mathrm{ml} / \mathrm{g}$ original fresh weight of tissue, and incubated with (a) $1 \mu \mathrm{M}\left[7-{ }^{3} \mathrm{H}\right]$ progesterone; (b) $1 \mu \mathrm{M} 17$-hydroxy $\left[4-{ }^{14} \mathrm{C}\right]$ progesterone; (c) $0.25 \mathrm{mM}$ NADPH; and (d) $0.05 \mathrm{M}$ potassium dihydrogen phosphate adjusted to $\mathrm{pH} 7.4$ with $2 \mathrm{M}$ potassium hydroxide. The total volume of each incubation mixture was 1 $\mathrm{ml}$; the incubation was at $37^{\circ} \mathrm{C}$ in a shaking water bath in tubes open to the air. The reaction was started by the addition of 0.05 $\mathrm{ml}$ of microsome suspension and quenched at selected times by the addition of $2 \mathrm{ml}$ of methanol containing $20 \mathrm{mg}$ of one or more of the following steroids: 17-hydroxyprogesterone, androstenedione, or testosterone. Although the corresponding cytosol stimulates androstenedione formation by rat testes microsomes, cytosol from adult rats prestimulated with hCG had no effect on testicular microsomes from humans who had been stimulated with hCG. In testes extracts prepared from Case 1, addition of the human cytosol fraction to the human microsomal fraction also had no effect on either the time course of testosterone synthesis or on the pattern of steroids produced. Consequently, cytosol was not routinely added during the incubations. Samples were stored at $-20^{\circ} \mathrm{C}$ until assayed. At the time of assay, each sample was diluted with water $(30 \mathrm{ml})$ and extracted 3 times with ethyl acetate $(30 \mathrm{ml}$ each, $90 \mathrm{ml}$ total). The organic phases were combined, evaporated to dryness with a rotary evaporator, and chromatographed on a $30 \times 1.9 \mathrm{~cm}$ Sephadex LH-20 column with the solvent isooctane:ethyl acetate:methanol ( $4: 1: 1$ by volume) (2). The material in each peak was acetylated with a mixture of pyridine and acetic anhyride (3:1) as previously described (2), and rechromatographed on the same column with the same solvent system. This column procedure has baseline separation for steroids differing in polarity by as little as the difference between an alcohol and a ketone with the same carbon skeleton. The capacity of the column is limited only by the solubility of the steroid in the solvent mixture. In representative samples, the carrier steroids were reisolated and crystallized to constant specific activity. In each case tested, the assignments of steroid identity were correct, and more than $90 \%$ of the activity in each chromatographic peak could be accounted for in the final specific activity of the reisolated steroid.

Serum steroid levels before and after hCG administration were measured by Dr. C. Migeon in Case 1 and 2 and by Endocrine Science, Tarzana, CA for Case 3.

Subjects. The clinical history of the children is shown in Table 1. Each had incomplete labial fusion, clitoromegaly, and hypospadias. Serum testosterone was determined before and after the administration of four daily doses of $\mathrm{hCG}\left(5000 \mathrm{IU} / \mathrm{m}^{2}\right.$ per dose) (19). While Case 1 had a marked increase in testosterone, neither Case 2 nor Case 3 showed a normal testosterone response $(>300$ $\mathrm{ng} / \mathrm{dl}$ after $\mathrm{hCG})$. The appearance of the external genitalia in these children was such that the female sex of rearing was deemed the more appropriate. Twenty-four to $48 \mathrm{~h}$ following the last dose of hCG, reconstructive surgery was performed and testicular tissue obtained $(0.5-1.0 \mathrm{~g}$ of tissue was used to prepare the microsomes). Histologic examination showed normal testicular histology in each case. Informed consent for the procedures was obtained from the parents. 


\section{RESULTS}

In order to select the appropriate time of incubation for recognition of defects, detailed time studies were performed for both Case 1 and Case 2. The results from Case 2 are shown in Figure 1. The material in Peak I (identified as progesterone) was almost completely metabolized during the first $10 \mathrm{~min}$. The Peak III steroids (17-hydroxyprogesterone and testosterone) reached a maximum at $5 \mathrm{~min}$ and then declined as the 17-hydroxyprogesterone was further metabolized to androstenedione which chromatographed separately in Peak II. Peak IV increased until progesterone was no longer present and was not further metabolized. The results from Case 1 differed from these only in that androstenedione did not accumulate. The amount of testosterone present in Peak III was quantitated after acetylation and rechromatography.

Table 1. Clinical presentation of the cases studied

\begin{tabular}{lrcc}
\hline & Case 1 & Case 2 & Case 3 \\
\hline Age (yr) & 1.93 & 9.0 & 0.04 \\
Karyotype & $46 \mathrm{XY}$ & $46 \mathrm{XY}$ & $47 \mathrm{XY}(+21)$ \\
Clitoromegaly & + & + & + \\
Labial fusion & + & + & + \\
Hypospadias & $3^{\circ}$ & $3^{\circ}$ & $3^{\circ}$ \\
Testosterone (ng/dl) & & & \\
$\quad$ Pre-hCG* & 32 & 42 & 31 \\
$\quad$ Post-hCG & 642 & 125 & 31 \\
Androstenedione (ng/dl) & & & \\
$\quad$ Pre-hCG & 36 & $\mathrm{NM} \dagger$ & 98 \\
$\quad$ Post-hCG & 181 & 249 & 91 \\
17-hydroxyprogesterone (ng/dl) & & & \\
$\quad$ Pre-hCG & 30 & $\mathrm{NM}$ & 56 \\
$\quad$ Post-hCG & 398 & 334 & 31 \\
Progesterone (ng/dl) & & & \\
$\quad$ Pre-hCG & 36 & $\mathrm{NM}$ & $\mathrm{NM}$ \\
$\quad$ Post-hCG & 106 & 89 & $\mathrm{NM}$ \\
\hline
\end{tabular}

* $5000 \mathrm{IU} \mathrm{hCG} / \mathrm{m}^{2} /$ day for 4 days; serum obtained $24 \mathrm{~h}$ after the late dose of hCG.

$\dagger \mathrm{NM}$, not measured.
In both cases almost all of the $\left[{ }^{3} \mathrm{H}\right]$ progesterone and a large portion of the 17 -hydroxy $\left[4-{ }^{14} \mathrm{C}\right]$ progesterone had been metabolized after $10 \mathrm{~min}$. Because the microsomes were resuspended in a volume according to the weight of tissue obtained, suspensions of microsomes from patients without enzyme blocks would have about the same enzymatic activity. Although the absolute amounts of each of the products changed with the time course, after 2 min of incubation, substantial amounts of testosterone were formed with Case 1 and with Case 2 after $5 \mathrm{~min}$ of incubation, substantial amounts of androstenedione were formed. Thus, the metabolic pattern was established within 5 min and in both cases more products accumulated at the 10 and 20 -min time points. To avoid the consequences of any possible alterations in Leydig cell density, the 10 -min time point was selected for presentation.

The chromatograms obtained following incubation of the testicular microsomes of Case 1 are shown in Figure 2. The pattern of tritium and carbon-14 label in each peak helps to confirm structural assignments based on chromatographic mobility and on cochromatography with each specific carrier. Peaks labeled only with tritium must be derived solely from progesterone and not from 17-hydroxyprogesterone. Thus, Peak I is labeled only with tritium and is progesterone, the starting material. The material in the region of the chromatogram labeled Peak II is not altered by attempted acetylation and contains both carbon14 and tritium labels; it has been identified as androstenedione on the basis of its label pattern and crystalization to constant specific activity with authentic material (2). In this instance, there is no definite peak of radioactivity in the region of Peak II as the androstenedione is rapidly metabolized and does not accumulate. The material in Peak III which contains both carbon-14 and tritium labels can be resolved into two peaks on rechromatography after acetylation as shown in Figure $2 B$. The peaks are testosterone acetate and 17-hydroxyprogesterone. The identity of the steroids in Peak IV is less clear. Acetylation and rechromatography resolve this material into two peaks, both of which have decreased polarity (Fig. $2 C$ ). The greater of these peaks contains only tritium label and cochromatographs with $16 \alpha$-hydroxyprogesterone (or $16 \beta$-hydroxyprogesterone) both as the free compound and as the acetate. As testicular homogenates

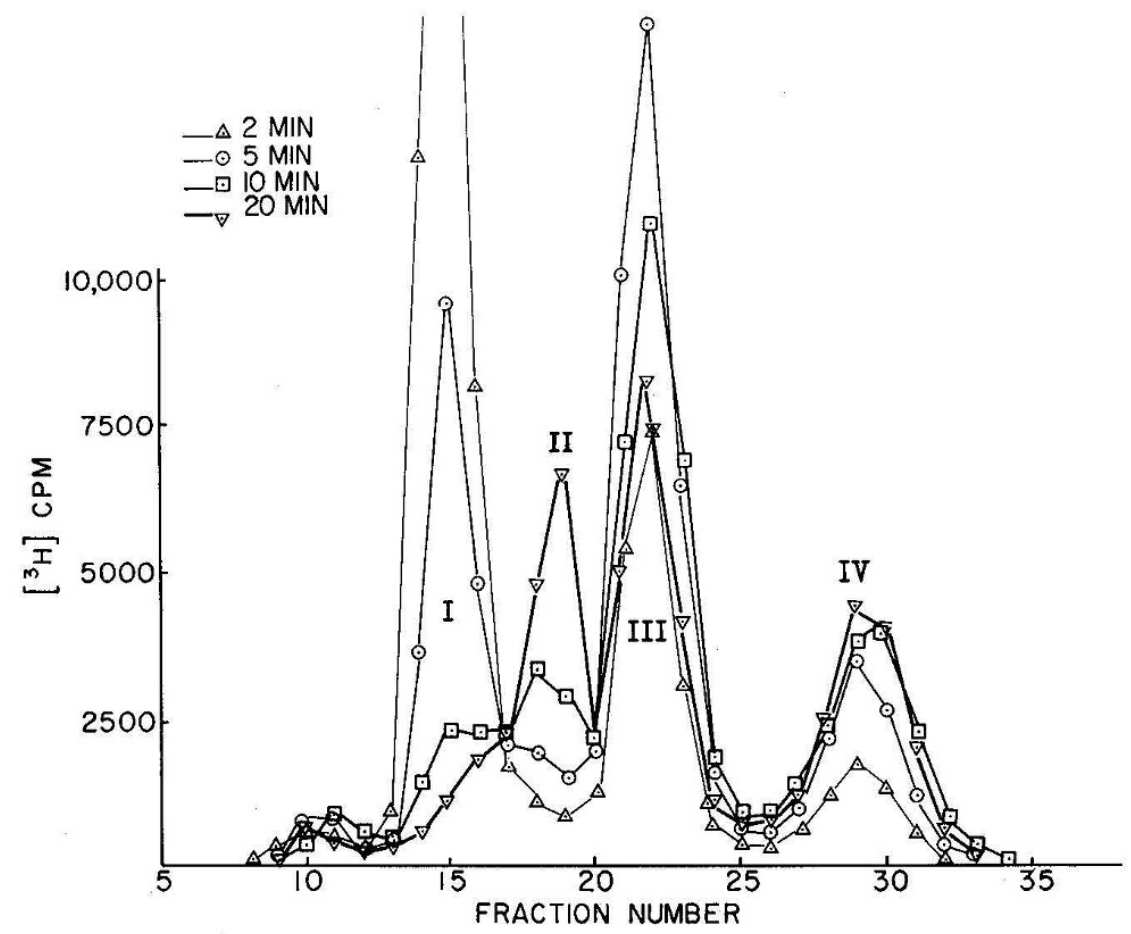

Fig. 1. Time course of $\left[7-{ }^{3} \mathrm{H}\right]$ progesterone metabolism. Sephadex LH-20 column chromatograms obtained from Case 2 after different periods of incubation. The peaks represent: $I$, progesterone; $I I$, androstenedione; $I I I$, testosterone and 17 -hydroxyprogesterone; $I V, 16 \alpha$-hydroxyprogesterone and $17 \alpha .20 \xi$-dihvdroxv-4-pregnen-3-one. 

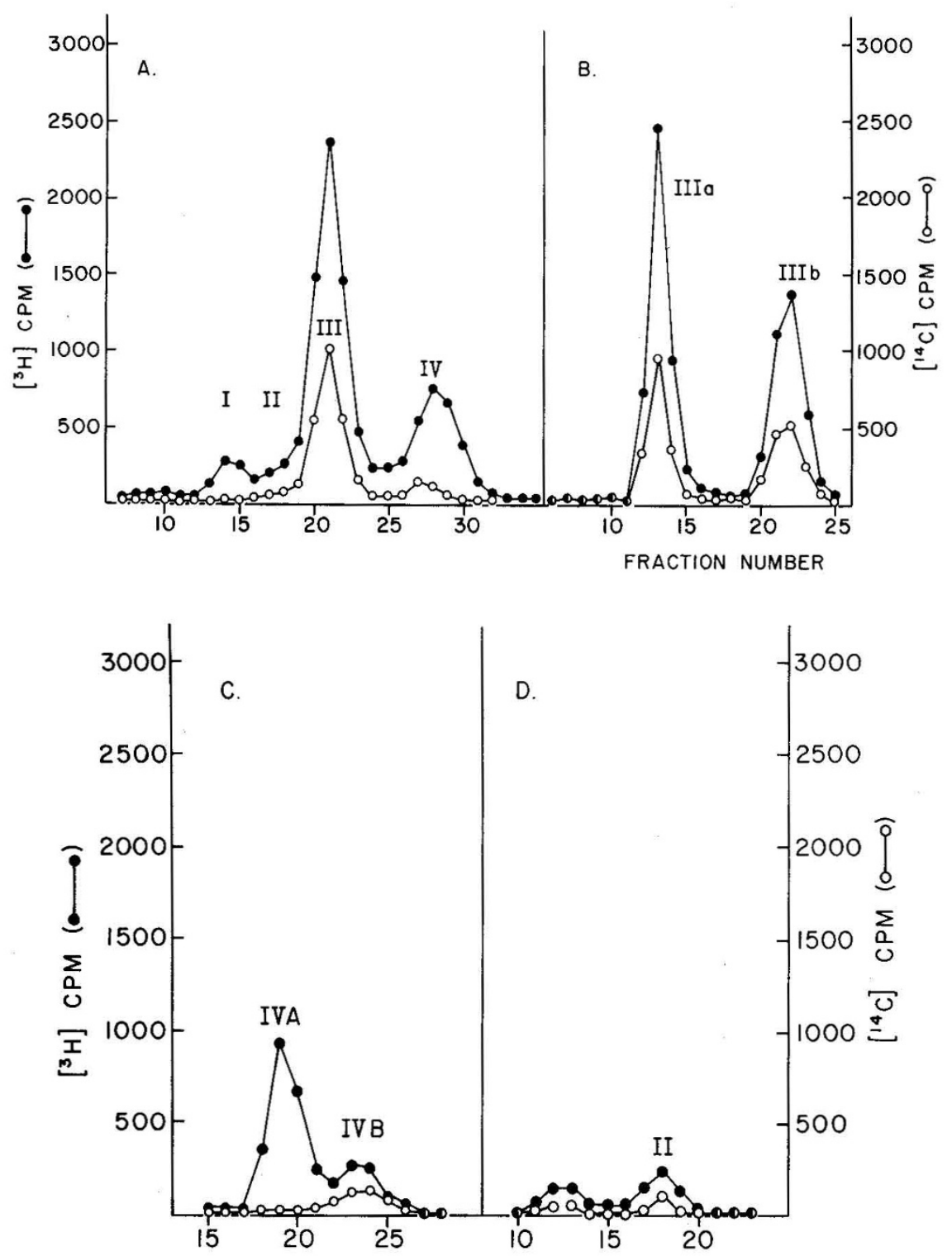

Fig. 2. Sephadex LH-20 column chromatograms from Case 1. $A$ is the original chromatogram obtained after $\left[7-{ }^{3} \mathrm{H}\right]$ progesterone and 17 hydroxy $\left[4-{ }^{14} \mathrm{C}\right]$ progesterone were incubated for $10 \mathrm{~min}$ with microsomes prepared from testes of Case $1 . B, C$, and $D$ show the rechromatography after acetylation of Peaks $I I I, I V$, and $I I$, respectively. The steroids are: Peak I, progesterone; $I I$, androstenedione; $I I I a$, testosterone acetate; IIIb, 17-hydroxyprogesterone; $I V a, 16 \alpha$-hydroxyprogesterone; and $I V b, 17 \alpha, 20 \xi$-dihydroxy-4-pregnen-3-one.

have been shown to produce $16 \alpha$-hydroxyprogesterone (11), the greater peak has been attributed to that compound. The lesser of the two peaks was also labeled with both carbon-14 and tritium and also formed an acetate under these mild conditions. One possible identity is $17 \alpha, 20 \xi$-dihydroxy-4-pregnen-3-one which has previously been shown to be synthesized in the testes (5) but there was insufficient labeled material to confirm this identification. Thus, in Case 1 (Fig. 2), testosterone was produced from both substrates, and this child did not have a defect in the enzymes that produce testosterone. The most likely cause of her phenotypic appearance is one of the androgen resistance syndromes but these can't be distinguished on the basis of testicular incubations (18).

Figure 3 shows the chromatograms obtained following testicular incubation in Case 2. Androstenedione (Peak II) was synthesized from both precursors but was not converted to testosterone. This finding confirmed a deficiency of 17-ketosteroid reductase which had been suggested by the observation that testosterone levels in this child did not increase normally following hCG treatment $(16,17)$.

The chromatographic results from Case 3 are shown in Figure 4. Neither androstenedione nor testosterone nor 17-hydroxy- progesterone increased following hCG treatment. The chromatogram shows no conversion of either progesterone or 17-hydroxyprogesterone to either testosterone or androstenedione. These results suggested that the patient had a defect in steroid-17,20lyase (20). In addition, although there was some conversion of progesterone to 17-hydroxyprogesterone, there was substantially less tritium in peak III B than was seen in the two other cases, and therefore there was also a considerable decrease in 17hydroxylase activity. The decrease in both 17-hydroxylase activity and steroid-17,20-lyase activity is consistent with her lack of stimulation of serum 17-hydroxyprogesterone levels in response to hCG shown in Table 1 and reported in a similar case by Kaufman et al. (7). The two defects are frequently closely associated because in the testes the two reactions are catalyzed by the same protein complex $(2,9)$. The defect in this enzyme complex can be distinguished from 17-hydroxylase deficiency on the basis of cortisol levels since the latter are extremely low in 17-hydroxylase deficiency (4). Our Case 3 had normal cortisol levels and thus has inadequate steroid-17,20-lyase catalytic activity. As there was little accumulation of radioactivity in the region of Peak IV, its nature could not be investigated with these samples.

Although our data are not complete, the same procedures have 


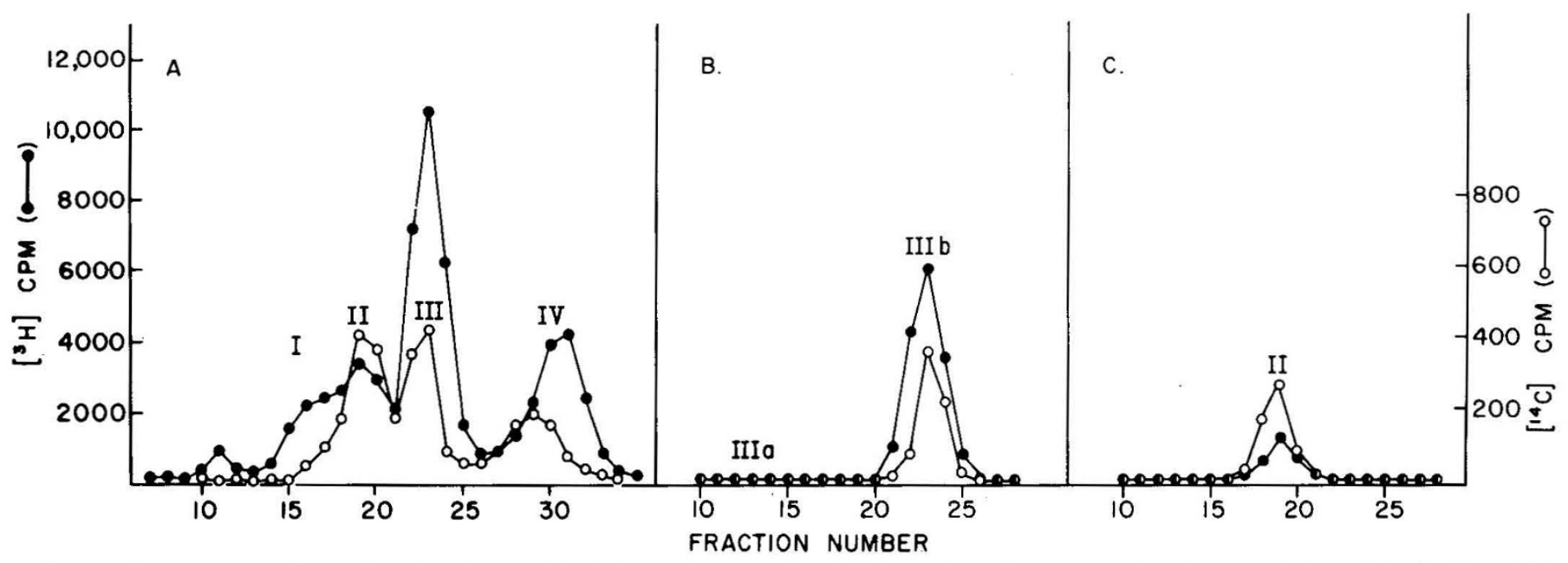

Fig. 3. Chromatograms from Case 2. $A$ is the original chromatogram. $B$ and $C$ show the rechromatography after acetylation of $P e a k s ~ I I I$ and $I I$, respectively. See Figure 2 for details.

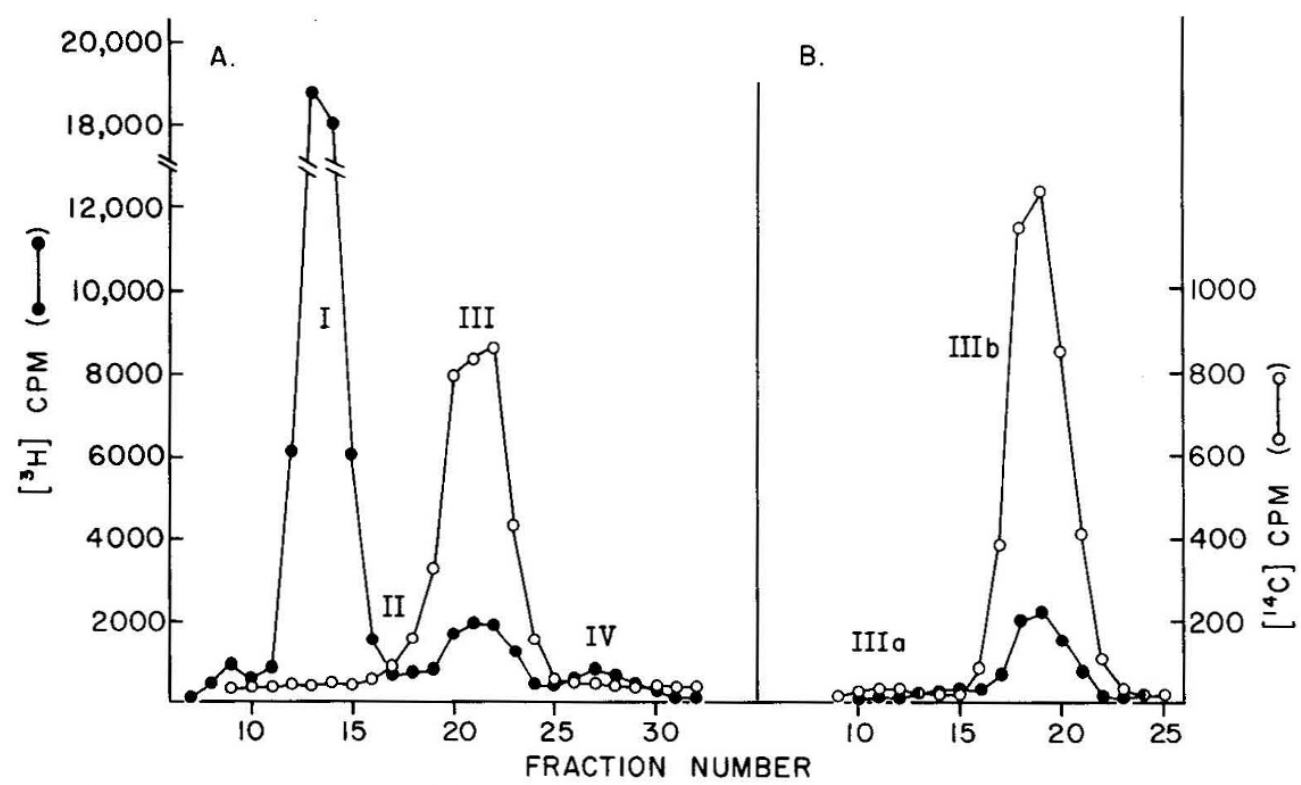

Fig. 4. Chromatograms from Case 3. A shows the original chromatogram from Case 3. B shows the rechromatography of Peak III. See Figure 2 for details. Note the differences in scale for ${ }^{3} \mathrm{H}$ and ${ }^{14} \mathrm{C}$.

been used to define the biosynthetic defect in four additional children. They had 46 XY karyotypes, clitoromegaly, hypospadias, and labial fusion just as the three cases described in detail in Table 1 and Figures 1-4. Of the additional cases, two made testosterone in vitro, one accumulated androstenedione, and one synthesized only 17 -hydroxyprogesterone. The serum steroid levels in response to hCG were consistent with the diagnosis of 17 -ketosteroid reductase and steroid-17,20-lyase deficiency, respectively.

\section{DISCUSSION}

The double-label, double-substrate mode of incubation has several advantages over single-label incubation procedures. When the reaction is allowed to proceed to only $70-80 \%$ of completion (10 min), the unreacted starting materials serve as internal references to aid the identification of the products. The labeling pattern for each peak $\left({ }^{3} \mathrm{H},{ }^{14} \mathrm{C}\right.$, or both) also aids the recognition of metabolites and pathways.

As long as sufficient products for characterization have been formed and have not all been metabolized by contaminating enzymes, the exact extent of reaction does not confuse the interpretation of the data. Since testosterone was present in Case 1 at the 2-min time point and remained until the 20 -min time point, which was the last time point studied, additional optimization of the incubation conditions is not necessary. RodriguezRigau et al. (14), who studied testosterone biosynthesis in biopsy samples from adults with oligospermia, have also found that the pattern of steroids produced is relatively persistent, and thus changes in the Leydig cell density do not limit the interpretation of the metabolic pattern. However, it should be noted that our method might not discriminate subtle partial enzymatic defects such as these authors reported (14).

Each of the defects in the conversion of progesterone to testosterone produces a characteristic chromatographic pattern. A defect in 17-hydroxylase would result in androgens labeled only from the carbon-14-containing substrate, 17-hydroxyprogesterone. A defect in steroid-17,20-lyase would lead to an accumulation of tritiated 17-hydroxyprogesterone but no conversion of either tritium or carbon-14 to androgens. A defect of 17 ketosteroid reductase would lead to the accumulation of androstenedione labeled with both carbon-14 and tritium but without the conversion of androstenedione to testosterone. When these studies were started, the appearance of testosterone in the chro- 
matograms after incubation with testicular microsomes was a surprise because microsomes from rat testes catalyze the formation of androstenedione from progesterone and require the interaction of the 17-ketosteroid reductase from the cytosol to produce testosterone (2). Thus, the situation in humans is different in two ways: first, 17-ketosteroid reductase is present in the newborn period (10) and second, during cell fractionation, it is isolated as a component of the microsomes. The combination of these two factors allows us to evaluate 17-ketosteroid reductase activity with our method of incubation. Thus, in a single incubation with two chromatograms, each of these three enzyme defects can be identified.

There are other steroid enzyme defects that can result in a failure of testosterone biosynthesis. Defects in the synthesis of progesterone from cholesterol are known and would not be detected with this in vitro assay system $(1,13)$. These children usually show evidence of defective salt regulation at birth. However, a recent report describes a family with $3 \beta$-hydroxysteroid dehydrogenase deficiency without salt loss (12). The male sibling did not respond to hCG with a rise in serum testosterone or progesterone levels. However, in such an individual, the pathway from progesterone to testosterone in the testes studied in vitro would be intact. Thus, a defect in this enzyme, whether or not it was associated with salt loss, would give a characteristic result: synthesis of testosterone in vitro but not in vivo. Therefore, $3 \beta-$ hydroxysteroid dehydrogenase deficiency also would give a characteristic result. Of the cases we studied, Cases 1 and 2 were able to synthesize progesterone in response to hCG. While progesterone levels were not measured in Case 3, testes from this individual were unable to metabolize progesterone to androgens in vitro and thus a cause of her problem was apparent.

One problem which has arisen when testosterone biosynthesis has been studied in testicular slices or homogenates is the production of $5 \alpha$-reduced substances. These are difficult to separate from their unreduced precursors. However, since in the human testes, the $5 \alpha$-reductase is found in the nucleus, it is separated from the microsomes by the low speed centrifugation step (unpublished observation). This eliminates the problems associated with separation and identification of the $5 \alpha$-reduced steroids.

In our laboratory, when we perform an incubation to identify a defect, we routinely (a) use several time points, (b) acetylate and rechromatograph each peak, and (c) crystallize at least a few samples to constant specific activity. However, such an extensive protocol is not necessary as study of the 10 -min time point usually provides all the information needed to confirm the presence or absence of an enzymatic defect.

The technique described here is useful in documenting androgen biosynthetic defects. The steroid pattern in serum following hCG stimulation and the pattern of steroids produced in vitro provide complementary approaches to the diagnosis of the various possible defects. Children with these problems are generally subjected to gonadectomy as the gonads are nonfunctional and prone to develop malignancies. Once the testes have been removed, the nature of the defect which caused the failure to virilize can never be reexamined. Therefore, we believe that a study of in vivo and of in vitro steroid responses to hCG should be undertaken at the time of surgery in order to obtain the most accurate diagnosis possible. As androgen insensitivity and defects in testosterone synthesis have different modes of inheritance, an incorrect diagnosis in such a child would lead to inaccurate counseling.

\section{REFERENCES AND NOTES}

1. Camacho AM, Kowarski A, Migeon CJ, Brough AJ 1968 Congenital adrenal hyperplasia due to a deficiency of one of the enzymes involved in the biosynthesis of pregnenolone. J Clin Endocrinol Metab 28:153

2. Chasalow F 1979 Mechanism and control of rat testicular steroidogenesis. J Biol Chem 254:3000

3. Chasalow F, Blethen SL, French FS 1982 An improved method for evaluating testosterone biosynthetic defects. Pediatr Res 16:345

4. D'Armiento M, Reda G, Kater C, Shackleton CHL, Biglieri EG $198317 \alpha-$ Hydroxylase deficiency: mineralocorticoid hormone profiles in an affected family. J Clin Endocrinol Metab 56:697

5. Fan DF, Oshima H, Troen BR, Troen P 1974 Studies of the human testis. IV. Testicular $20 \alpha$-hydroxysteroid dehydrogenase and steroid $17 \alpha$-hydroxylase. Biochim Biophys Acta 360:88

6. Goebelsmann U, Hall TD, Paul WL, Stanczyk FZ 1975 In vitro steroid metabolic studies in testicular $17 \beta$-reduction deficiency. J Clin Endocrinol Metab 41:1136

7. Kaufman FR, Costin G, Goebelsmann U, Stanczyk F, Zachmann M 1983 Male pseudohermaphroditism due to 17,20-desmolase deficiency. J Clin Endocrinol Metab 57:32

8. Kershnar AK, Borut D, Kogut MD, Biglieri EG, Schambellan M 1976 Studies in a phenotypic female with 17-alpha-hydroxylase deficiency. J Pediatr $89: 395$

9. Nakajin S, Shively JE, Yuan P-M, Hall PF 1981 Microsomal cytochrome P450 from neonatal pig testis: two enzymatic activities (17 $\alpha$-hydroxylase and C-17,20-lyase) associated with one protein. Biochemistry 20:4037

10. Oshima H, Ishiwata D, Hatakeyama S, Yokokawa M 1980 In vitro steroidogenesis in testes of three infants, two with ambiguous external genitalia and one with true precocious puberty: evidence for the presence of active $17 \beta-$ hydroxysteroid oxidoreductase in immature human testes. Endocrinol Jpn 27:59

11. Oshima H, Sarada T, Ochi-Ai K, Tamaoki B-I 1967 Intracellular distribution and properties of steroid $16 \alpha$-hydroxylase in human testes. J Clin Endocrinol Metab 27:1249

12. Pang S, Levine LS, Stoner E, Opitz JM, Pollack MS, DuPont B, New MI 1983 Non-salt-losing congenital adrenal hyperplasia due to $3 \beta$-hydroxysteroid dehydrogenase deficiency with normal glomerulosa function. J Clin Endocrinol Metab 56:808

13. Parks GA, Bermudez JA, Anast CS, Bongiovanni AM, New MI 1971 Pubertal boy with the $3 \beta$-hydroxysteroid dehydrogenase defect. J Clin Endocrinol Metab 33:269

14. Rodriguez-Rigau LJ, Weiss DB, Smith KD, Steinberger E 1978 Suggestion of abnormal testicular steroidogenesis in some oligospermic men. Acta Endocrinol 87:400

15. Rosenfield RL, Rich BH, Wolfsdorf JI, Cassorla F, Parks JS, Bongiovanni AM, Wu CH, Shackleton CHL 1980 Pubertal presentation of congenital $\triangle 5-3 \beta-$ hydroxysteroid dehydrogenase deficiency. J Clin Endocrinol Metab 51:345

16. Saez JM, Frederich A, Bertrand J 1971 Endocrine and metabolic studies in children with male pseudohermaphroditism. J Clin Endocrinol Metab 32:611

17. Saez JM, Morera AM, DePeretti E, Bertrand J 1972 Further in vitro studies in male pseudohermaphroditism with gynecomastia due to a testicular 17 . ketosteroid reductase defect (compared to a case of testicular feminization). J Clin Endocrinol Metab 34:598

18. Wilson JD, Griffin JE, Leshin M, MacDonald PC 1983 The androgen resistance syndromes: $5 \alpha$-reductase deficiency, testicular feminization, and related disorders. In "The Metabolic Basis of Inherited Disease" (J. B. Stanbury, J. B. Wyngaarden, D. S. Fredrickson, J. L. Goldstein, and M. S. Brown, eds.), pp. 1001-1026. McGraw-Hill Book Company, New York, 1983.

19. Zachmann M 1974 Evaluation of gonadal function in childhood and adolescence. Helv Paediatr Acta Suppl 34:53

20. Zachmann M, Vollmin JA, Hamilton W, Prader A 1972 Steroid -17,20desmolase deficiency: a new cause of male pseudohermaphroditism. Clin Endocrin 1:369

21. This work was supported in part by Grant HD 11678 from the National Institute for Child Health and Human Development and Grant RR36 from the General Clinical Research Centers Program of the Division of Research Resources, National Institutes of Health. Presented in part at the combined meeting of the American Pediatric Society and the Society for Pediatric Research, May 6, 1982, Washington, D. C.

22. We would like to thank Dr. Claude Migeon for his help with the steroid assays on the serum samples of Case 1 and 2 and Aileen Derhake and Kim Kendall for help in the preparation of the manuscript.

23. Requests for reprints may be addressed to Dr. Fred Chasalow, Schneider Children's Hospital, Division of Endocrinology, Long Island Jewish-Hillside Medical Center, New Hyde Park, NY 11042

24. Received for publication December 7, 1983. 